\title{
Trends and Challenges in Adoption of E-Payment Services in India
}

\author{
S.Karunakaran, A.Sivakumar, J.Balaji, D.Kumaresan, D.Muralidhar
}

\begin{abstract}
Electronic payment services are vastly growing market around the world due to its convenience and quickness. After demonetization in India during 2016, the proliferation payment systems reached the peak with in-house service providers and global operators explore here. The proposed analysis work focus on creating conscious about different factors related to e-Payment Systems with its cons, objections and security features. The historical data and referent have been taken out in order to acquire essential data about electronic payments systems. This study on outlook of e-payment systems was carried out following search of several research directions on digital payment services. As there are multiple service providers, the digital vision will be fully utilized only by raising awareness among people and society with the huge popularity of internet and technology. To realize their success parameters, it is vital to examine the strategies of general consumers, cyber merchants, network managers, banks and other public sector organizations. Disappointed experiences may lead to establishment of a new payment system. Our results highlight straight forward explanations of the success factors of electronic payment services in India based on variety of features. The study also reveals the popularity of e-payment services in India on various criteria.
\end{abstract}

Keywords: Electronic-Commerce, Payment Gateway, Digital Payment, Security

\section{INTRODUCTION}

EPayment service is a element of e-commerce transaction to contain electronic payment for purchasing goods and services provided through the internet[1]. Digital payment is a monetary interchange that was carried out online connecting buyers and sellers by electronic means without using actual cash. The aim of this procedure is normally some type of digital fiscal tool such as encrypted credit card digit, electronic cheques or digi-cash. Online e-payment system is a function that enables the public to take online disbursement for their shopping[2][3]. We have analyzed common payment

Revised Manuscript Received on April 11, 2020.

* Correspondence Author

Dr.S.Karunakaran*, AP/Computer Technology, Kongu Engineering College College, Perundurai, India. Email: karunakarankrs@gmail.com

Dr.A.Sivakumar, AP/Mechanical, Kongu Engineering College College, Perundurai, India. Email: askmech@kongu.ac.in

J.Balaji, Final Year B.Sc CSD, Kongu Engineering College College, Perundurai, India.

D.Kumaresan, Final Year B.Sc CSD, Kongu Engineering College College, Perundurai, India.

D.Muralidhar, Final Year B.Sc CSD, Kongu Engineering College College, Perundurai, India.

(C) The Authors. Published by Blue Eyes Intelligence Engineering and Sciences Publication (BEIESP). This is an open access article under the CC BY-NC-ND license (http://creativecommons.org/licenses/by-nc-nd/4.0/) gateways in India including PayPal, GooglePay, Paytm, Amazon pay, Phonepe. The proposed work gives an in depth description aimed to increase consciousness on electronic payments. The varied definitions of an E-payment and its connected aspects had been provided. Payment services covered by essential protection concerns of E-commerce[4]. E-payment gateway representation and the clarification of its miscellaneous safety requirements and mechanisms are discussed.

\section{PAYMENT GATEWAYS IN INDIA}

\section{A. Google Pay}

Google Pay applies Near Field Communication (NFC) to broadcast card information facilitating funds move to the retailer. NFC replaces the credit card and debit card chip and PIN or magnetic stripe deal at point-of-sale terminals by empowering the user to upload these in the Google Pay wallet. It is comparable to contactless payments previously used in many countries, with the inclusion of two-factor authentication.

Google Pay is an superior wallet stage and online installment structure created by Google to manage in-application and tap-to-pay buys on mobile phones, allowing clients to create installments with Android mobiles, tablets or watches.

\section{B. PayPal}

The PayPal stage empowers designers to make applications that can make buys for the benefit of outsider clients, without the clients being diverted to paypal.com to finish the installment exchanges. Such trader started billings for non-repeating/non-membership installments incorporate adaptive payments pre-endorsements and express checkout reference exchanges.

\section{PhonePe}

The PhonePe application available in India is accessible in 11 Indian languages. With PhonePe, clients can send and get rupees, DTH recharge, information cards, carry out utility installments, buy gold and shop on the internet and offline. In addition, PhonePe permits clients to book Ola rides, pay for Redbus tickets, request nourishment on freshmen, eaf, fit and benefit Goibibo Flight and Hotel benefits through micro-apps on its foundation.

\section{Paytm}


Paytm payment gateway is currently supports 12 Indian languages and offer online provision that include mobile top-ups, service bill payments, tour, movies, and events booking, store payments at domestic and international shops, fruits and vegetable stores, restaurants, parking, toll-gate, Hospital, medicines and academic institutions using the Paytm QR code. California based PayPal had filed a case against Paytm in the Indian trademark office for using a logo similar to its own on 18 November 2016.As of January 2018, Paytm is valued at $\$ 10$ billion and it is planning to launch its initial public offering (IPO) in 2022

\section{E. Amazon Pay}

Amazon Pay is an online installments preparing administration that is possessed by Amazon. Propelled in 2007, Amazon Pay utilizes the shopper base of Amazon.com and spotlights on giving clients the alternative to pay with their Amazon accounts on outer trader sites. Amazon Pay gives the choice to buy products and enterprises from sites and versatile applications utilizing the addresses and installment strategies put away in the amazons account.

\section{F. Others}

Web banking programming gives individual and corporate financial administrations offering highlights, seeing record adjusts, acquiring proclamations, checking late exchanges, moving cash among records and making installments[5]. It can be done by using credits and debit cards and they supports different methods of payments. IMPS, NEFT, RTGS are used to transfer funds from one account to another[6][7].

\section{SECURITY FEATURES}

\section{A. Google Pay}

- Payment statistics, cryptography for merchants.

- The Google Pay API returns payment ways in a notably signed and encrypted Payment methodology Token payload. They came few ways by both cards that comprise PAN and tokenism cards. It contains machine permanent account number and crypto-grams.

- Typical data load contains a field that specifies the protocol edition that informs the receiver of the consignment about crypto-logic scenarios used and as a result the expected format.

- This afford particulars to establish a public key in order to demand a Google signed plus encrypted indict move toward token, and little print the steps to need affirming and decipher the token. The above numbers applies exclusively to protocol description = ECv2.

- The following steps define what an integrator has to do to consume the Google Pay API ECv2 payment procedure coupon payload.

- Acquire Google origin sign key.

- Confirm that symbol of the center key is genuine through available signing keys.

- Check the in-between sign type of the data portion to ensure data is still alive.

- Ensure the mark of the load is legal by applying in between signing-key.

- Next, decrypt the filling of the payload after carefully verifying the genuineness of the sign.
- Ensure that communication is still alive. This can be done by comparing the present time with the communication expiration time in the decrypted load.

\section{B. PhonePe}

There are two key capacities that the term covers.

- Ensuring that these subtleties are certified and not phony or fake.

- While physical character is genuinely simple to confirm, checking one's advanced personality isn't as basic.

- The procedure rotates around confirming two confirmation factors something physical you have, and a bit of secret data you know.

- On account of ATM exchanges, your bank card is the thing that you have, and your PIN is the thing that you need to make sure to do the exchange.

- UPI exploits that and joins itself with your portable number for distinguishing proof.

- At the point when you pursue an UPI application, your telephone sends a push SMS for check purposes. This guarantees that no one can duplicate the OTP from another gadget.

- Utilizing push SMSes ties your gadget to your portable number and should be revamped each time you change your gadget.

\section{Key UPI features that boost security}

The selling purpose of the UPI stage is that your cash never leaves your record your exchange is finished. There is no middle of the road step where an outsider gets access to your cash. To put it plainly, UPI exchanges are immediate financial balance to ledger exchanges.

The way PhonePe works, you simply need the payee's bank connected portable number to make an exchange, given that they are a PhonePe client as well. This expels the need to share private subtleties like financial balance number and IFSC number. As a stage made by the NPCI, UPI will have further security combinations later on[8].

Making UPI Aadhar/UIDAI prepared is accounted for to be in the pipeline for UPI 2.0, and if that occurs, UPI will have reconciliations with Aadhar's biometric database. This will give it an additional degree of biometric based security later on[9][10].

\section{Paytm}

Paytm is PCI DSS consistent as far as security is concerned. Preserve CVV of client to ensure their credit and optimistic unique proof subtleties are completely sheltered. Currently every monetary interchange with Paytm is in the course of 128-piece complex SSL protection. User tend to moreover associate continuously perception and gathering activity motor to evacuate suspicious exchanges and ensure the client's money is generally secure.

\section{E. PayPpal}

The SSL/TLS conventions are the reason for secure interchanges on the web. They are additionally under steady assault. Security specialists attempt to remain one stride in front of digital aggressors by examining the SSL/TLS conventions for vulnerabilities. Recommend certain practices to follow for the best practices.

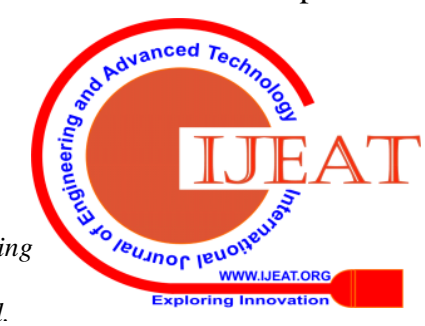


- Discontinue use of the VeriSign G2 Root Certificate

- Upgrade to SHA-256 SSL certificates

- Use TLS version 1.2 or higher

- Let the protocol negotiate the highest version

- Do not hard code specific ciphers

- Allow Perfect Forward Secrecy

- Stay vigilant

\section{F. Amazon Pay}

Transport Security Layer ("TLS") and Secure Sockets Layer ("SSL") are conventions intended to guarantee that information can be safely moved between a web server and a program utilizing cryptographic calculations. TLS/SSL guarantees that the information transmitted originates from the source it professes to be originating from and has not been altered or perused by an outsider during the transmission.

- TLS/SSL testaments: TLS/SSL utilizes testaments to make sure about and secure transmitted information. An authentication contains data about the proprietor of the testament, for example, the association, nation, span of legitimacy, site address, and the declaration ID of the individual who guarantees (signs) this data. It contains additionally the open key and a hash to guarantee that the declaration has not been altered.

- Security: The primary reason for using a TLS/SSL certificate is to keep data exchanged between a buyer's browser and your server secure. This prevents order and payment details or buyer data, such as the buyer's username and password from being exposed to the internet and intercepted.

- Buyer Trust: When you purchase a TLS/SSL certificate, the Certificate Authority will issue a seal to be displayed on your web page. This seal instills trust in your website when buyers know their data is secure.

Table-I: Comparison of Features

\begin{tabular}{|c|c|}
\hline GooglePay & $\begin{array}{l}\text {-Snappy and Easy approach to send } \\
\text { and get cash. } \\
\text { - Different cash back and prizes } \\
\text { benefits. } \\
\text { - Encryption and different layers of } \\
\text { security by Google to make sure about } \\
\text { exchange. } \\
\text { - Cover Utility tabs, energize your } \\
\text { versatile and do web based shopping } \\
\text { utilizing this application. } \\
\text { - No extra expense of use. } \\
\text { - This application can likewise be } \\
\text { - Combilized for business reason. } \\
\text { - no charge is included } \\
\text { - Send and Receive Money through } \\
\text { - Takdio } \\
\text { - Various Payment Options } \\
\text { - Prizes } \\
\text { - Advance offer }\end{array}$ \\
\hline PhonePe & $\begin{array}{l}\text { - } \text { Credit and Debit Card Linking } \\
\text { - Bank Balance Check } \\
\text { - Cash Storage } \\
\text { - Application to Bank Account } \\
\text { - Send and Receive Money } \\
\text { - POS Payments }\end{array}$ \\
\hline
\end{tabular}

\begin{tabular}{|c|c|}
\hline & $\begin{array}{l}\text { - } \text { PIN Authorization } \\
\text { - Financial balance Linking } \\
\text { - Wallet Top Ups }\end{array}$ \\
\hline Paytm & $\begin{array}{l}\text { - } \text { Trader Payment } \\
\text { - Store Transfer } \\
\text { - Portable Recharge } \\
\text { - Bill Payment } \\
\text { - Advanced Gold } \\
\text { - Monetary Investment } \\
\text { - Film Tickets } \\
\text { - Travel Tickets } \\
\text { - Instalment Bank } \\
\text { - Mess around } \\
\text { - Paytm History }\end{array}$ \\
\hline AmazonPay & $\begin{array}{l}\text { - } \text { Programmed Payments } \\
\text { - Character } \\
\text { - Inline Checkout } \\
\text { - Dealer Website Integration } \\
\text { - Extortion Protection }\end{array}$ \\
\hline PayPal & $\begin{array}{l}\text { - Acknowledge Payments Online } \\
\text { - Scanner tag Scanning } \\
\text { - Charge Me Later } \\
\text { - Charge card Reader } \\
\text { - Express Checkout } \\
\text { - Stock Tracking } \\
\text { - Portable Card Reader } \\
\text { - Internet Invoicing } \\
\text { - PCI Compliance } \\
\text { - Shopping basket } \\
\text { - Virtual Terminal } \\
\end{array}$ \\
\hline
\end{tabular}

\section{METHODOLOGY}

To review the features of e-payment systems, in the proposed work various reports are prepared as analysis results such as categories wise total values report, excellent values report for companies, categories values comparison report for companies (ascending/descending order), security type excellent values report for companies (ascending/descending order). It also surveys the features such as 1) Mobile Payments, 2) On Form Payments, 3) Recurring Billing, 4) Requires SSL, 5) Phone Support and 6) Email Support features.

- The results ensure that the data set was collected by real time survey and data are more Trust worth and reliable.

- The survey conducted by team and data were collected from students, faculties, supporting staffs, bank employees and common public around Kongu Engineering College, Perundurai, India.

- Survey taken from 300 peoples using questionnaire and remarks are given under categories such as gateways user friendliness, security aspects and bank connectivity.

- Survey results are converted into data $\operatorname{set}(0$ 's and 1's) using Microsoft excel

- Data set (csv) file used in R tool and to get desire graph as output for simulation.

\section{Advantages}

Published By:

Blue Eyes Intelligence Engineering \& Sciences Publication

(C) Copyright: All rights reserved.

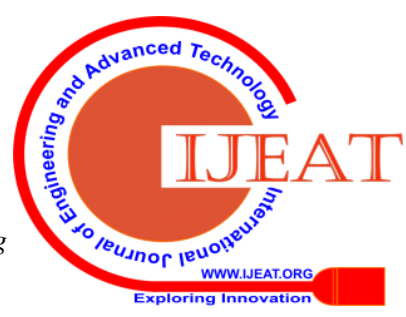


- Analysis is made related with features support count given by payment companies to the customers.

- Practical customer feedback data regarding secure payment system are presented.
- Comparison is made between service providers with real time customer oriented data.

- Suitable for analytical purpose in terms of customer feedback.

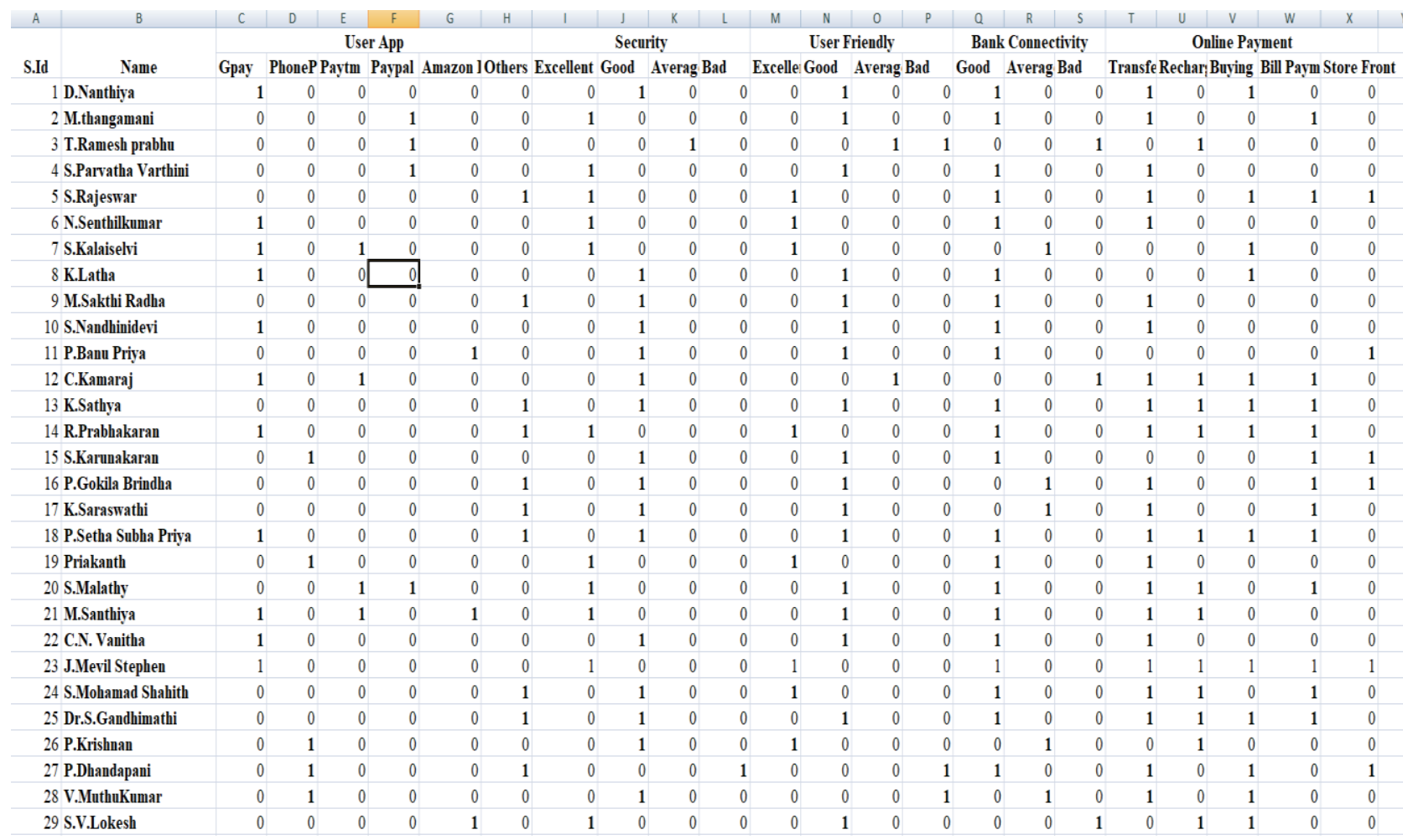

Fig 1. Sample Data Set

\section{RESULT AND DISCUSSION}

In this part, "gpaydata.csv", "phonepaydata.csv", "paypaldata.csv", "paytmdata.csv" and "othersdata.csv" files are taken as data set each of which contains 300 records. Security, User Friendliness and Bank Connectivity wise Excellent, Good, Average and Bad details are fetched. The record value is either 0 or 1 . The details are collectively stored in a data frame for further processes.

Here, Excellent total, Good total, Average total and Bad total for all companies individually are calculated and plotted using barplot(). Hence category wise total value report is prepared. Four charts are plotted separately as well as a comparison chart in a single barplot() is also prepared and displayed. Again the same details are plotted with descending order based on the count.

Excellent total values for Security type only is prepared for all companies. The chart contains Company name in $\mathrm{X}$ axis and count in $\mathrm{Y}$ axis. Separate charts are plotted one for ascending order of count and the other for descending order of count.
User friendly features dataset is prepared which is taken from the base paper table. The companies taken are: 1) Paypal standard, 2) Paypal Pro, 3) Authorize.net, 4) 2CheckOut, 5) Stripe, 6) Brain Tee, 7) WePay, 8) Amazon Payment, 9) Dwolla, 10) Bean Stream, 11) Chargify and 12) First Data. The features taken are: 1) Mobile Payments, 2) On Form Payments, 3) Recurring Billing, 4) RequiresSSL, 5) Phone Support and 6) Email Support. Either 0 or 1 is the value in the table.

The graph results shows the value of execellent ,good,average and bad for gpay,paytm,pahonepe ,amazon,paypal and other payment gateways. This clearly represent that the gpay has higer excellent value and low bad values. The graph also clearly shows the gpay has the high security specifications.50 percent feedback is voted for gpay as excellent in security . 


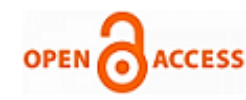

International Journal of Engineering and Advanced Technology (IJEAT)

CATEGORY WISE TOTAL VALUES REPORT ( Amazon )

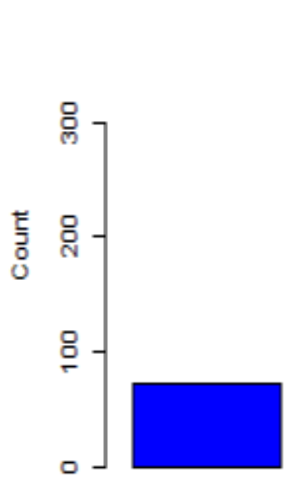

Excelent

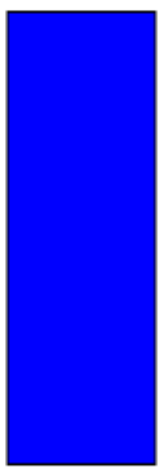

$$
\text { Good Category }
$$

CATEGORY WISE TOTAL VALUES REPORT ( PhonePe )
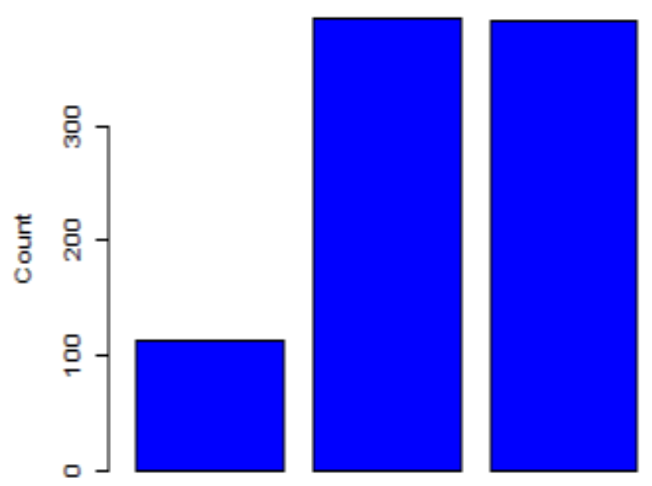

Good

Average

Category

CATEGORY WISE TOTAL VALUES REPORT ( PayTM )

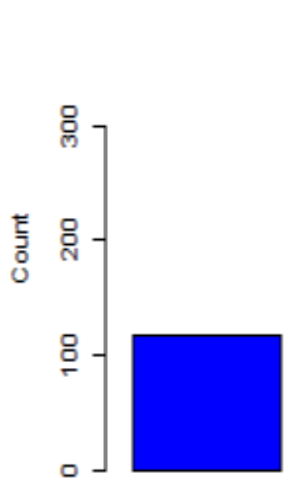

Excelent
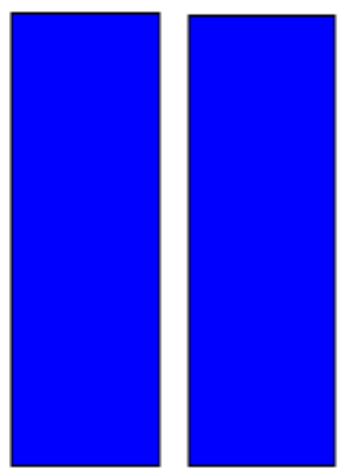

Good

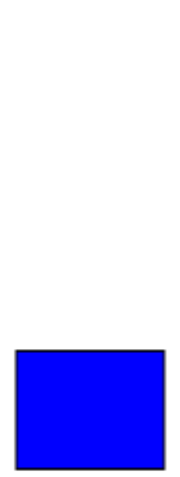

Bad ISSN: 2249 - 8958 (Online), Volume-9 Issue-4, April 2020

CATEGORY WISE TOTAL VALUES REPORT ( GPay )

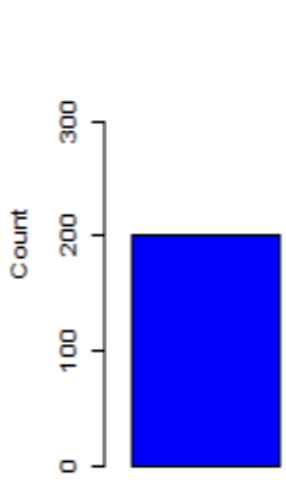

Excelent

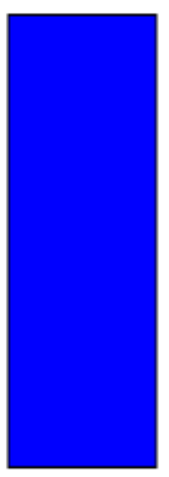

Good

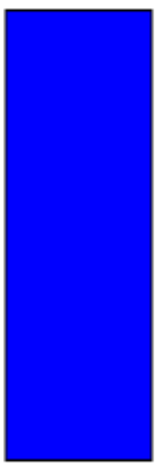

Average

Category

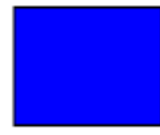

Bad
CATEGORY WISE TOTAL VALUES REPORT ( Paypal )

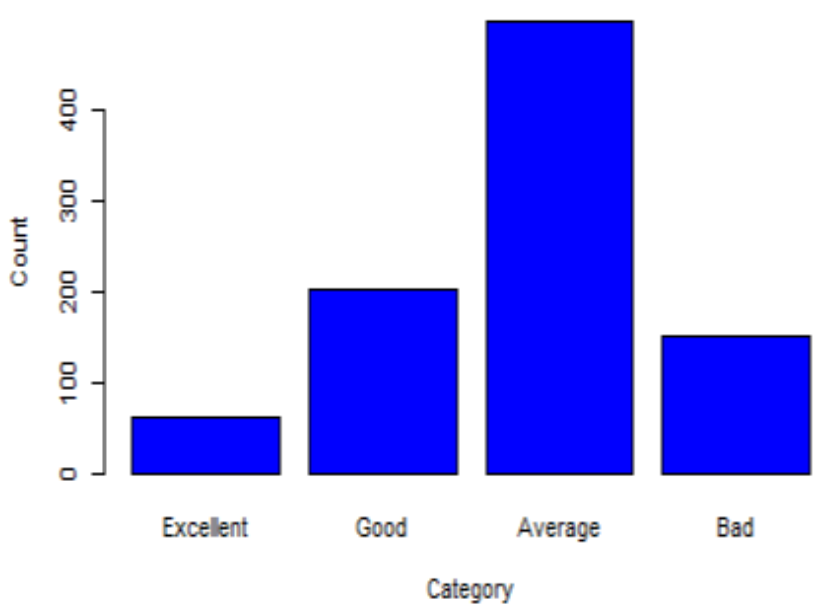

CATEGORY WISE TOTAL VALUES REPORT ( Others )
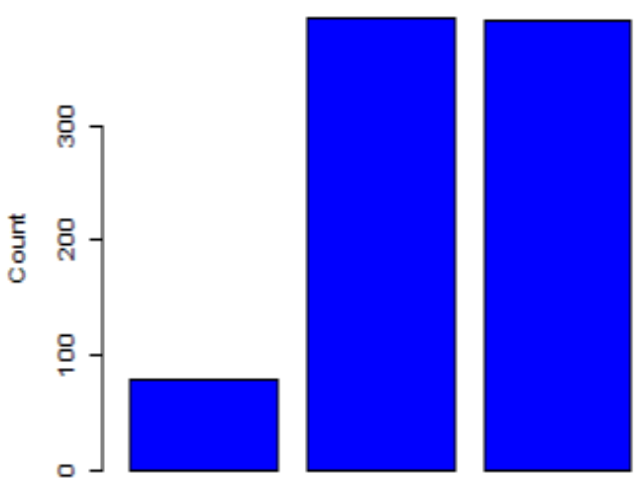

Good

Average

Bad Category Category

Fig 2. Customer Feedback on General

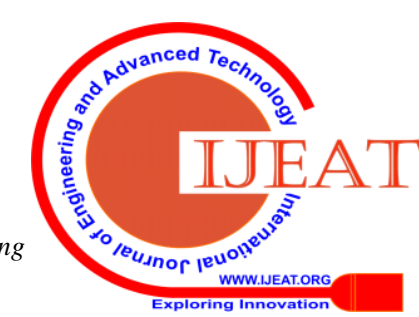


Trends and Challenges in Adoption of E-Payment Services in India

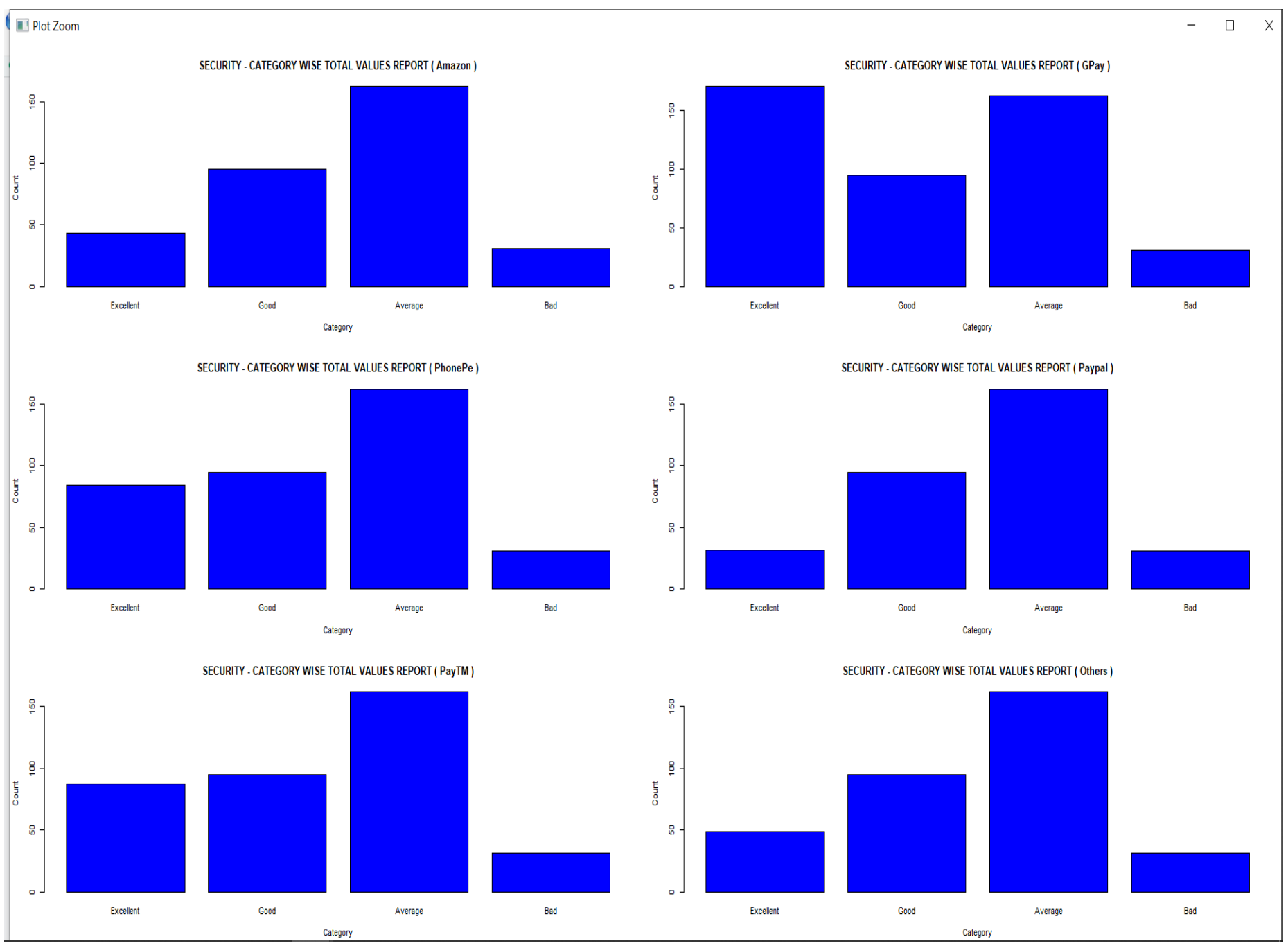

Fig 3. Customer Feedback on Overall Security Aspect

[1] Plot Loom

SECURITY - Excellent VALUES REPORT FOR COMPANIES

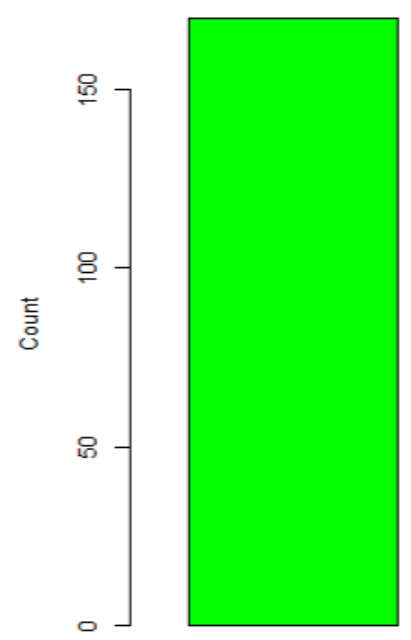

GPay

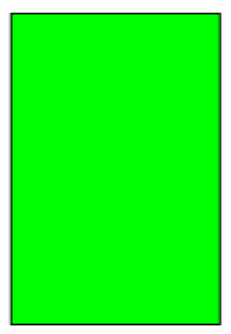

PayTM

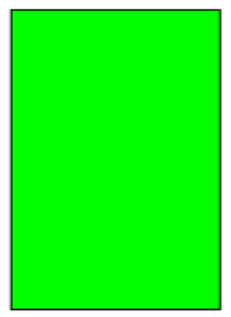

PhonePe

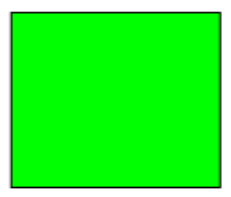

Others

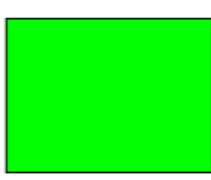

Amazon

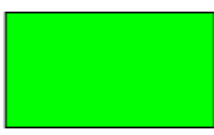

Paypal

Fig 4. Customer Feedback on Excellent Security

Published By:

Blue Eyes Intelligence Engineering

\& Sciences Publication

(C) Convriaht: All riahts reserved.

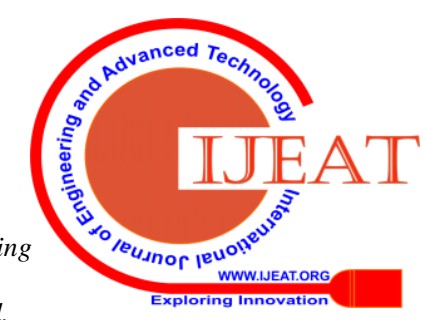




\section{CONCLUSION}

In current digital environment, payments catch the form of money transaction as electronic shape. The E-Payment options have been accepted and proven to be most important payment method worldwide. This article reveals the customer experience in different parameters while using popular payment gateway systems that are currently used in India. The survey is conducted among different category of customers across multiple domains. Top payment methods including Amazon, Phonepe, Paypal, Gpay, Paytm were investigated. The analysis results show that the Google Pay service proves to be more efficient in providing best experience for users.

\section{REFERENCES}

1. Sun J, Ahluwalia P, Koong KS. "The more secure the better? A study of information security readiness" Industrial Management and Data Systems. 2011 Apr 26; 111(4): 570-88. Crossref

2. Aigbe $P$, Akpojaro J. "Analysis of security issues in electronic payment systems” International Journal of Computer Applications. 2014 Jan 1; 108(10):10-4. Crossref

3. Ayo CK, Adewoye JO, Oni AA. "The state of e-banking implementation in Nigeria: A post-consolidation review" Journal of Emerging Trends in Economics and Management Sciences. 2010; 1(1):37-45.

4. Oyewole OS, Abba M, El-maude JG. "E-banking and bank performance: Evidence from Nigeria", International Journal of Scientific Engineering and Technology (IJSET). 2013; 2(8):766-71.

5. Oyewole OS, El-Maude JG, Abba M, Onuh ME. "Electronic payment system and economic growth: a review of transition to cashless economy in Nigeria" International Journal of Scientific and Engineering Research. 2013; 2(9):913-8.

6. Singh A, Singh K, Shahazad, Khan MH, Chandra M. "A review: secure payment system for electronic transaction”, International Journal of Advanced Research in Computer Science and Software Engineering. 2012 Mar; 2(3): 236-43.

7. Shilpa, Sharma P. "Advance technique for online payment security in e-commerce: Double Verification”, International Journal on Computer Science and Engineering. 2013 Jun 1; 5(6):508

8. Abrazhevich D. "Electronic payment systems: A usercentered perspective and interaction design" Dennis Abrazhevich; Eindhoven, Netherland: Technische. 2004; 1-202.

9. Roy S, Sinha I. "Determinants of customers' acceptance of electronic payment system in Indian banking sector-a study", International Journal of Scientific and Engineering Research. 2014; 5(1):177-87.

10. Kabir MA, Saidin SZ, Ahmi A. "Adoption of e-payment systems: a review of literature", International Conference on E-Commerce, Kuching, Sarawak. 2015. p. 112-20.

\section{AUTHORS PROFILE}

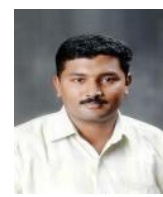

Dr. S. Karunakaran was born on March 15, 1979 in Erode. He received B.Sc., Degree in Computer Science from Nagamalai Navarasam Arts and Science College, Bharathiar University, Coimbatore, TamilNadu, India in 1999; Master of Computer Applications degree from Kongu Engineering College, Bharathiar University, Coimbatore, India in 2002 and M. Phil., degree in Computer Science from Manonmaniam Sundaranar University, Tirunelveli, India in 2003; Ph.D in Computer Science from Anna University Chennai in 2012. He became member of IEEE in 2007. Presenly, he is working as an Assistant Professor (SRG), in the School of Computer Technology and Applications, at Kongu Engineering College, Perundurai, Erode, Tamilnadu, India. He has been in the teaching profession for the past 16 years. He has guided 8 post graduate projects and 34 under graduate projects over these years. He has published 10 papers in International Journals, 12 papers in International Conference and Presented 21 papers in National Conferences. His academic interests include ad-hoc networks, distributed computing and wireless communication.

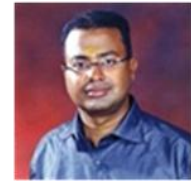

Dr.A.Sivakumar working as full-time faculty member of Mechanical Engineering Department in Kongu Engineering College (Autonomous) affiliated by Anna university Chennai at Perundurai TamilNadu. Did his postgraduate and research at NIT Tiruchirapalli. Specialization is Engineering optimization and industrial Engineering. Published 13 international journal and 22 international renowned conferences conducted by IITs, IISc, NITIE, IIMs and NITs. Actively involved in sponsored projects funded by UGC. Current fields of interest are engineering optimization, maintenance policy and artificial intelligence. Member of IIIE,MISTE and fellowship in Institution of Engineers (India) -FIE 